ScIDice

\section{Efficacy of Push Out Bond Strength of Proroot Mta, Biodentine \& Calcium Phosphate Cement Ondentin: An Ex-Vivo Evaluation}

Research Article

Vanita Dattatraya Revankar ${ }^{1 *}$, Kaarunya Ravikumar ${ }^{2}$, Mallikarjun D.Y ${ }^{3}$, Gautam Ranjit ${ }^{4}$, T.Sathish kumar ${ }^{5}$, S.Anabarasu ${ }^{6}$

${ }^{1}$ Reader, Department of Conservative Dentistry and Endodontics, Vinayaka Mission Sankarachariyar Dental College, Vinayaka Mission's Research Foundation [Deemed To Be University], Salem, Tamil Nadu, India.

${ }^{2}$ Sr.Lecturer,Department of Conservative Dentistry and Endodontics,Vinayaka Mission Sankarachariyar Dental College, Vinayaka Mission's Research Foundation [Deemed To Be University], Salem, Tamil Nadu, India.

${ }^{3}$ Sr.Lecturer,Department of Conservative Dentistry and Endodontics,Vinayaka Mission Sankarachariyar Dental College, Vinayaka Mission's Research Foundation [Deemed To Be University], Salem, Tamil Nadu, India.

${ }^{4}$ Sr.Lecturer,Department of Conservative Dentistry and Endodontics,Vinayaka Mission Sankarachariyar Dental College, Vinayaka Mission's Research Foundation [Deemed To Be University], Salem, Tamil Nadu, India.

${ }^{5}$ Professor and Head (Dept.of Oral Maxillofacial Surgery), Govt. Mohan kumaramangalam Medical College \& Hospital, Salem, Tamil Nadu, India.

${ }^{6}$ Assistant Professor, (Dept.of Conservative Dentistry \& Endodontics) Govt. Mohan Kumaramangalam Medical College \& Hospital, Salem, India.

\title{
Abstract
}

Introduction: It is well known that the biomineralization process leading to the synthesis of an interfacial layer with tag-like structures is due to the synergeticeffect of mineral trioxide aggregate (MTA) \& Portland Cement with dentin in phosphatebuffered saline (PBS) at the cement-dentin interface. However, there are no investigations which have examined the effect of the influence of biomineralization process on the push-out bond strength of ProRoot MTA (Dentsply Tulsa Dental, Tulsa,OK), Biodentine \& Calcium phosphate cement (BioGraft CPC).

Aim: To examine the effect of biomineralization process on the push-out strength of ProRoot MTA, Biodentine \& CPC after mixing with $0.2 \%$ Chlorhexidine gluconate solution and 2\% local anaesthetic solution on the bond strength of MTA-dentin. Materials and Methods: Dentin discs with uniform cavities were filled with ProRoot MTA, Biodentine \& Calcium Phosphate Cement. The samples were equally divided into two groups: experimental group being immersed in PBS and control group being immersed in Saline for 2 months. Instron Testing machine (Model 4444; Instron Corp, Canton, MA) was utilised for determining the bond strength. Statistical analysis used: A two-way analysis of variance \& post hoc analysis by Bonferroni test.

Results: Specimens inserted into PBS showed a significant resistance to dislodgement than that detected for the samples of Saline $(\mathrm{p}<0.05)$. MTA \& Biodentine exhibited higher resistance to dislodgement than Calcium Phosphate Cements.

Conclusion: It was concluded that the push-out bond strength of the cement mainly the MTA \& Biodentine groups, were positively benefitted by the biomineralization process.

Keywords: Biomineralization; Carbonated Apatite; Biodentine; Calcium Phosphate; Cement Mineral Trioxide Aggregate.

\section{Introduction}

In the present time of regenerative endodontics, endless studies in the area of bio-materials, has brought back original form and function of even the most difficult cases a reality [1]. Iatrogenic complications of endodontic treatment like perforations can occur advancing to endodontic failure.[2]
Many materials like amalgam, Super EBA, IRM, Cavit, Composite Resin and Glass Ionomer Cements have been used in the past to seal perforation sites. These materials have their own disadvantages like microleakage, toxicity and sensitivity in the presence of moisture.

MTA exhibits very good biocompatibility, greater sealing efficien-

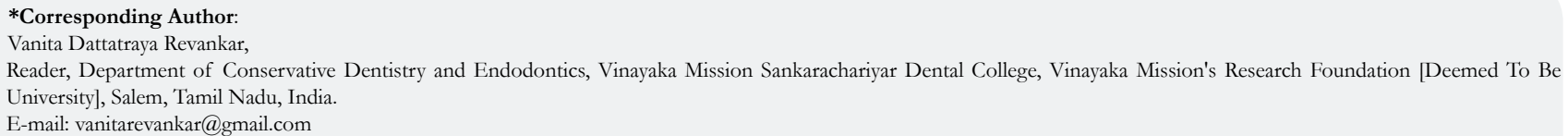

Citation: Vanita Dattatraya Revankar, Kaarunya Ravikumar, Mallikarjun D.Y, Gautam Ranjit, T. Sathish Kumar, S.Anabarasu. Efficacy of Push Out Bond Strength of Proroot MTA, Biodentine \& Calcium Phosphate Cement Ondentin: An Ex-Vivo Evaluation. Int J Dentistry Oral Sci. 2021;8(8):3678-3681.doi: http://dx.doi.org/10.19070/2377-8075-21000753

Copyright: Vanita Dattatraya Revankar 2021 . This is an open-access article distributed under the terms of the Creative Commons Attribution License, which permits unrestricted use, distribution and reproduction in any medium, provided the original author and source are credited. 
cy and capacity to set in the presence of blood.[3] A colloidal gel is formed on the hydration of the powder which solidifies in less than 4 hours to a hard structure.[4] Lately, many, new Calcium Silicate based Materials have been popularized including BioAggregate, MTA-Angelus, Calcium Phosphate Cement and Biodentine, Biodentine is a calcium-silicate based material that has been introduced in recent years and has been suggested to use in many clinical applications, such as root perforations, apexification, resorptions, retrograde fillings, pulp capping procedures, and dentine replacement.

Calcium phosphate cement (CPC) [5] consist of uniform amounts of tetracalcium phosphate (TTCP) and dicalcium phosphate anhydrous (DCPA) was exhibited to be biocompatible [6] and osteoconductive.

Though, the query is as to if these medications will possibly trigger chemical reaction to debase MTA, Biodentine \& CPC or impede with its bond to dentin has not been well stated in the earlier studies.

'The aim of this study was to compare \& detect the effect of $0.2 \%$ CHX \& $2 \%$ LA on the bond strength of PROROOT-MTA, Biodentine \& CPC dentin in vitro.

\section{Materials And Method}

The study was done in the department of conservative dentistry ad endodontics after obtaining ethical approval from institutional ethics committee. One hundred \& twenty human premolars extracted for orthodontic purposes were utilised in the present study.

The crowns were detached and mid-root dentin was diagonally sectioned into $2.00 \mathrm{~mm}$ wide segment with a water cooled lowspeed carborundum disc. With a spherical diamond bur,the area of the canal was broadened and two complete passes of a \#5 Gates-Glidden bur was done to get $1.3 \mathrm{~mm}$ diameter uniform cavities. The segments were inserted in 17\% EDTA for 3 minutes proceeded by $1 \%$ sodium hypochlorite for 3 minutes. They were then cleaned in distilled water immediately and desiccated.

One hundred \& twenty sectioned teeth samples were split into two uniform groups, one being control group A and the other being experimental group B. Each group was further divided into 6 sub-groups.

o Sub-Group 1A: Samples were filled with ProRoot MTA mixed with $0.2 \%$ Chlorhexidine gluconate solution \& immersed in Saline. o Sub-Group 2A: Samples were filled with ProRoot MTA mixed with a Local anaesthetic solution (Lidocaine HCL- 2\%) \& immersed in Saline.

o Sub-Group 3A: Samples were filled with CPC mixed with $0.2 \%$ Chlorhexidine gluconate solution \& immersed in Saline.

o Sub-Group 4A: Samples were filled with CPC mixed with a Local anaesthetic solution (Lidocaine HCL- 2\%) \& immersed in Saline.

o Sub-Group 5A: Samples were filled with Biodentine mixed with $0.2 \%$ Chlorhexidine gluconate solution \& immersed in Saline.

o Sub-Group 6A: Samples were filled with Biodentine mixed with a Local anaesthetic solution (Lidocaine HCL- 2\%) \& immersed in Saline.

Similarly,

o Sub-Group 1B: Samples were filled with ProRoot MTA mixed with $0.2 \%$ Chlorhexidine gluconate solution \& immersed in PBS solution.

o Sub-Group 2B: Samples were filled with ProRoot MTA mixed with a Local anaesthetic solution (Lidocaine HCL- 2\%) \& immersed in PBS solution.

o Sub-Group 3B: Samples were filled with CPC mixed with $0.2 \%$ Chlorhexidine gluconate solution \& immersed in PBS solution. o Sub-Group 4B: Samples were filled with CPC mixed with a Local anaesthetic solution (Lidocaine HCL- 2\%) \& immersed in PBS solution.

o Sub-Group 5B: Samples were filled with Biodentine mixed with $0.2 \%$ Chlorhexidine gluconate solution $\&$ immersed in PBS solution.

o Sub-Group 6B: Samples were filled with Biodentine mixed with a Local anaesthetic solution (Lidocaine HCL- 2\%) \& immersed in PBS solution.

ProRoot MTA, CPC \& Biodentine powder was mixed with $0.2 \%$ CHX solution \& $2 \%$ LA at a powder-liquid ratio of $3: 1$. When the mixture showed putty consistency, it was compacted with a plugger into root canals with a help of a carrier. All samples wereassessed using a microscope at $16 \mathrm{X}$ magnification. Samples with cracks, defects or gaps between the material and dentin walls were excluded.

Immediately after filling, 10 samples from the control group (A) were placed in a saline solution of $15 \mathrm{ml}(\mathrm{Ph}=7.2)$ for 2 months at 37- degree centigrade \& experimental group (B) were placed in phosphate buffer solution. The solution was changed once in every 5 days.

Push-out Test: After experimental periods,specimens were kept in a steel holder which was firmed to an aligning apparatus that held it centered below a steel piece with a cylindrical punch. Bond strengths were measured.using an MTS testing machine.

The barrel shaped end of a 2/4 hand plugger with $1 \mathrm{~mm}$ diameter was utilizedas a force probe placed on the moving head of the MTS. The force probe moving at a speed of $0.2 \mathrm{~mm} / \mathrm{min}$, enforced pressure to the surfaces of MTA in all samples until the material was dislodged. The maximum force used to MTA before displacement taken place was noted as $\mathrm{N}$ force.

All values were fed into the computer and checked by means of SPSS 16.0 system for windows. A two-way analysis of variance comparisons with 5\% significance level was done to test the differences in dislodgement force between the twelve groups. A post hoc analysis by Bonferroni test was performed within the same cement type inserted in PBS \& Saline solutions.

\section{Results}

Two-way ANOVA analysis exhibitted that the mean values showed a statistically significant variance in the mean expulsion force among the CPC and all other sub-groups (table1). 
Table 1. Demonstrates the comparison in between the mean bond strength of each subgroup.

\begin{tabular}{|c|c|c|c|c|c|c|c|}
\hline \multirow[t]{2}{*}{ Group } & \multirow[t]{2}{*}{ Number } & \multirow[t]{2}{*}{ Mean } & \multirow{2}{*}{$\begin{array}{c}\text { Std. } \\
\text { Deviation }\end{array}$} & \multicolumn{2}{|c|}{$\begin{array}{l}\text { 95\% Confidence Interval for } \\
\text { Mean }\end{array}$} & \multirow[t]{2}{*}{ Minimum } & \multirow{2}{*}{$\begin{array}{l}\text { Maxi- } \\
\text { mum }\end{array}$} \\
\hline & & & & Lower Bound & Upper Bound & & \\
\hline Saline $1 \mathrm{~A}$ & 10 & 26.47 & 6.81 & 21.60 & 31.34 & 15.58 & 35.54 \\
\hline solution $2 \mathrm{~A}$ & 10 & 26.11 & 10.84 & 18.36 & 33.86 & 9.86 & 43.84 \\
\hline $3 \mathrm{~A}$ & 10 & 13.01 & 4.40 & 9.87 & 16.16 & 6.82 & 21.68 \\
\hline $4 \mathrm{~A}$ & 10 & 10.70 & 4.02 & 7.82 & 13.57 & 5.36 & 18.80 \\
\hline $5 \mathrm{~A}$ & 10 & 28.18 & 10.10 & 20.95 & 35.40 & 10.16 & 41.43 \\
\hline $6 \mathrm{~A}$ & 10 & 25.72 & 1125 & 17.67 & 33.76 & 1268 & 38.86 \\
\hline Total & 60 & 21.70 & 10.75 & 18.92 & 24.47 & 5.36 & 43.84 \\
\hline PBS 1B & 10 & 34.79 & 9. & 27.81 & 41.76 & 20.46 & 46.32 \\
\hline Solution 2B & 10 & 33.71 & 4.41 & 30.55 & 36.87 & $2 \mathrm{a} 40$ & 36.40 \\
\hline $3 \mathrm{~B}$ & 10 & 21.12 & 5.40 & 17.26 & 24.98 & 16.61 & 32.36 \\
\hline $4 \mathrm{~B}$ & 10 & 20.37 & 5.59 & 16.37 & 24.37 & 14.60 & 30.60 \\
\hline $5 B$ & 10 & 40.57 & 11.12 & 32.61 & 48.52 & 20.19 & 54.56 \\
\hline $6 \mathrm{~B}$ & 10 & 3420 & 4.81 & 30.76 & 37.64 & 26.78 & 42.68 \\
\hline Total & 60 & 30.79 & 1028 & 28.14 & 33.45 & 14.60 & 54.56 \\
\hline
\end{tabular}

Table 2. Demonstrates the comparison in between the mean bond strength of each subgroup.

Post hoc analysis by bonferroni test

Dependent Variable: Parameter

\begin{tabular}{|c|c|c|c|c|c|c|}
\hline \multicolumn{3}{|c|}{ subgroup } & \multirow{2}{*}{$\begin{array}{c}\text { Mean } \\
\text { Difference (1.J) } \\
8.315 \\
\end{array}$} & \multirow{2}{*}{$\begin{array}{c}\text { Std.Error } \\
3.760 \\
\end{array}$} & \multirow{2}{*}{$\begin{array}{c}\mathbf{p} \\
0.040\end{array}$} & \multirow[b]{2}{*}{ sig } \\
\hline S with & $\mathrm{p}$ & $\mathrm{BC}$ & & & & \\
\hline & & $\mathrm{BL}$ & 7.602 & 3.700 & 0.045 & sig \\
\hline & & $\mathrm{cc}$ & 8.106 & 2.202 & 0.002 & HS \\
\hline & & CL & 9.674 & 2.178 & 0.000 & HS \\
\hline & & PC & 12.389 & 4.750 & 0.018 & $\operatorname{sig}$ \\
\hline & & PL & $8.4 \mathrm{~S} 3$ & 3.868 & 0.042 & sig \\
\hline
\end{tabular}

$\mathrm{S}=$ Saline solution, $\mathrm{P}=\mathrm{PBS}$ solution, $\mathrm{HS}=$ highly significant, sig=significant

The mean dislodgement force of MTA-dentin reduced in/the control group. The greatest degree of mean dislodgment force was exhibitted by MTA \& Biodentine subgroups. Table 1 demonstrates the comparison in between the mean bond strength of each subgroup. Bonferroni test was applied to perform a comparison among individual groups. The results showed that among the samples inserted in Saline $(\mathrm{P}>0.05)$, samples inserted in PBS showed a significantly higher resistance to displacement as shown in table 2 . Bond strength was significantly higher in subgroups $1 \mathrm{~B}$, $2 \mathrm{~B}, 5 \mathrm{~B} \& 6 \mathrm{~B}$ than in the others $(\mathrm{P}>0.05)$.

There was no statistically significant variationin the mean dislodgment force between the $0.2 \%$ Chlorhexidine gluconate \& $2 \%$ LA subgroups. Subgroups 3B \&4B exhibited significantly low amount of bond strengths then compared with other subgroups.

\section{Discussion}

MTA has been used in both surgical and nonsurgical utilization, along with root-end fillings, [7-10] direct pulp cappings [11, 12], perforation repairs in roots or furcations $[13,14]$ and apexification.[15] In functional areas MTA should not be placed, because of its low compressive strength [16]. Biodentine and MTA are applied in pulp capping due to their active role in mineralized tissue bridge formation, the maintenance of pulpal vitality, and facilitation of odontoblast layer integrity [17] For health-care providers and dentists, Biodentine is new bioactive cement that is similar to the widely used MTA.

With concern to dentin bridge formation, it was noted that Biodentine and MTA are likely to favour the formation of reparative dentin, and they have direct results on odontoblasts when applied in Direct Pulp Capping Procedures.

Root perforations can be remodeled by using materials like Calcium phosphate cement(CPCs). They coalescence the osteocompatability and biocompatibility of hydroxyapatite implants and mouldability of acrylic bone cement and are extremely versatile in applications. The most frequently used solutions are saline, chlorhexidine, Local anaesthesia \& $\mathrm{NaOCl}$, etc. There are not many previous literatures which have stated that these agents would potentially stimulate chemical interaction to debase MTA \& Biodentin or reduce its bond to dentine.Saline and Local anesthetic solutions are commonly mixed with Portland-derived cement be- 
cause of its easier handling and availability in clinical procedures. The present research was designed to check the effect of the biomineralization mechanism which resisted dislodgement of different types of cement from the dentinal wall.This study has evaluated the effects of $0.2 \%$ chlorhexidine and $2 \%$ LA on the bond strength of ProRoot MTA, Biodentine \& CPC-dentin in vitro. The mean values of push-out bond strength all the experimental groups are in accordance with the results of previous literatures 18-20, which also assessed the push-out test for other purposes. The present study displayed that all PBS-immersed samples exhibited a significantly greater resistance to dislodgement compared to the control group $\&$ also displayed statistically significant difference in the mean dislodgment force between theMTA, Biodentine and CPC groups. No statistical significant difference was noted between $2 \%$ LA and $0.12 \%$ chlorhexidine groups.

MTA promotes the precipitation of carbonated apatite, stimulating a controlled mineral nucleation on dentin as the production of an interfacial layer with tag-like structures.[18] Even though, all cement form tag-like structures when inserted in PBS, it is necessary to figure out that the samples of ProRoot MTA \&Biodentine displayed statistically significant resistance to dislodgement than the CPC.

Reduced mechanical properties of CPC are the main drawback of this material. Since the material is weak under tensile forces.[19] The particle size of cement also influences variation in push-out strength. It is clearly established that the variations in the particle size of the material tested are of higher significant for the mechanical characteristics of the bound cement. Therefore, the usage of cement with an uneven size of fragments may not be ideal, in cases when higher forces could be placed with the cement, when used as a permanent restoration.

\section{Conclusion}

The main conclusion of this study was that the biomineralization process showed positive influence on the resistance to displacement from dentin of all cement tested. However, MTA \& Biodentine benefited more than CPC from the process.However, more researches are needed before this cement can safely be used in clinical practice.

\section{References}

[1]. Clauder T, SHIN SJ. Repair of perforations with MTA: clinical applications and mechanisms of action. Endod Top. 2009 Nov;15(1):32-55.

[2]. Main C, Mirzayan N, Shabahang S, Torabinejad M. Repair of root perforations using mineral trioxide aggregate: a long-term study. J Endod. $2004 \mathrm{Feb}$ $1 ; 30(2): 80-3$.

[3]. Ford TR, Torabinejad M, McKendry DJ, Hong CU, Kariyawasam SP. Use of mineral trioxide aggregate for repair of furcal perforations. Oral Surg Oral Med Oral Pathol Oral Radiol Endod. 1995 Jun 1;79(6):756-63.

[4]. Torabinejad M, Watson T, Pittford T R. Sealing ability of MTA when used as a root end filling material. J Endod 1993;19:591-595.

[5]. Hong YC, Wang JT, Hong CY, Brown WE, Chow LC. The periapical tissue reactions to a calcium phosphate cement in the teeth of monkeys. J Biomed Mater Res. 1991 Apr;25(4):485-98.

[6]. Kamerer DB, Hirsch BE, Snyderman CH, Costantino P, Friedman CD. Hydroxyapatite cement: a new method for achieving watertight closure in transtemporal surgery. Am J Otol. 1994 Jan;15(1):47-9.Pubmed PMID: 8109630 .

[7]. Torabinejad M, Hong CU, Ford TR, Kariyawasam SP. Tissue reaction to implanted super-EBA and mineral trioxide aggregate in the mandible of guinea pigs: a preliminary report. J Endod. 1995 Nov 1;21(11):569-71.

[8]. Torabinejad M, Pitt Ford TR, Abedi HR,Tang HM. Tibia and mandible reactions to implanted root-end filling materials. J Endod. 1997;23:263.

[9]. Torabinejad M, Hong CU, Lee SJ, Monsef M, Ford TR. Investigation of mineral trioxide aggregate for root-end filling in dogs. J Endod. 1995 Dec 1;21(12):603-8.

[10]. Torabinejad M, Ford TR, McKendry DJ, Abedi HR, Miller DA, Kariyawasam SP. Histologic assessment of mineral trioxide aggregate as a root-end filling in monkeys. J Endod. 1997 Apr 1;23(4):225-8.

[11]. FORD TR, Torabinejad M, Abedi HR, Bakland LK, KARIYAWASAM SP. Using mineral trioxide aggregate as a pulp-capping material. J Am Dent Assoc. 1996 Oct 1;127(10):1491-4.

[12]. Abedi HR, Torabinejad M, Pitt Ford TR, Bakland LK. The use of mineral trioxide aggregate cement (MTA) as a direct pulp capping agent. J Endod. 1996 Apr;22(4):199.

[13]. Myers K, Kaminski E, Lautenschlager E, Miller D. The effects of mineral trioxide aggregate on the dog pulp. J Endod. 1996 Apr;22(4):198-202.

[14]. Shabahang S, Boyne PJ, Abedi HR,McMillan P, Torabinejad M. Apexification in immature dog teeth using osteogenic protein-1, mineral trioxide aggregate, and calcium hydroxide. J Endod. 1997;23:265.

[15]. Abedi HR, Ingle JI. Mineral trioxide aggregate: a review of a new cement. J Calif Dent Assoc. 1995 Dec 1;23(12):36-9.

[16]. Torabinejad M, Hong CU, McDonald F, Ford TP. Physical and chemical properties of a new root-end filling material. J Endod. 1995 Jul 1;21(7):34953.

[17]. De Rossi A, Silva LA, Gatón-Hernández P, Sousa-Neto MD, Nelson-Filho P, Silva RA, et al. Comparison of pulpal responses to pulpotomy and pulp capping with biodentine and mineral trioxide aggregate in dogs. J Endod. 2014 Sep;40(9):1362-9.Pubmed PMID: 25146016.

[18]. Reyes-Carmona JF, Felippe MS, Felippe WT. Biomineralization ability and interaction of mineral trioxide aggregate and white portland cement with dentin in a phosphate-containing fluid. J Endod. 2009 May;35(5):731-6. Pubmed PMID: 19410094.

[19]. Ambard AJ, Mueninghoff L. Calcium phosphate cement: review of mechanical and biological properties. J Prosthodont. 2006 Sep;15(5):321-8. 